\title{
Closed systems and the rearing of fish larvae
}

\author{
W. P. DAvis \\ Aquatic Sciences, Inc.; Boca Raton, Florida, USA
}

KURZFASSUNG: Geschlossene Systeme und die Zucht von Fischlarven. Verschiedene Anordnungen und Verfahren zur Aufzucht von Fischlarven in geschlossenen Wassersystemen werden gegenwärtig entwickelt und geprüift. Die Auswahl der hierfür benutzten Fischarten erfolgt im Hinblick auf fortpflanzungsbiologische und ökologische Besonderheiten. Der Einfluß von Temperatur, Salzgehalt, Nährstoffen, Licht, autotrophen Organismen sowie der Wasserzirkulation werden anhand der Aufzuchterfolge erörtert. Einige Methoden für die Aufzucht von Fischbrut und Jungfischen werden kurz erläutert.

\section{IN'T'RODUCTION}

This paper serves as a preliminary report on present research in the field of laboratory cultivation of aquatic (fresh-water and marine) organisms in closed systems at Aquatic Sciences, Inc., Boca Raton, Florida. Additional information on the facility and aims of this organization is given in KALBER's (1970) paper in this symposium volume.

\section{PROCEDURE AND RESULTS}

At the present time successful routine cultivation of marine fishes in closed water systems appears to be an uncommon practice. Typically researchers studying physiology or development of marine fishes rely on sources of "wild" or natural sea water. With our facility in Florida, we theoretically have an excellent source of natural sea water immediately available to us. However, related to human pollution factors in natural sea water, it is necessary in most of our experiments, especially in those investigating the effects of pesticides, to utilize closed systems and artificial sea water. This paper is by necessity a preliminary report since at this date we have raised only a few marine fishes in our system. This is not to say that we have failed to raise many, but that our efforts are concentrated upon a small number of species which are applied to answer specific questions investigating requirements of fish larvae in closed systems.

When one reviews the various characteristics desired to be controlled in any system, it quickly becomes apparent why the majority of workers use natural sea water: "simplicity". The planning required to develop and build our present systems 
and experiments support this fact. As an example it is necessary in controlling water circulation to control separately water movement in the immediate environment of the organism, and in the net exchange between the immediate environment to outside water processing chambers. The requirement creates two separate types of circulation problems, each with associated considerations and solutions. Circulating water after leaving the organism's culture chamber typically passes through sensors, linked to separate, but integrated, controllers for the parameters of temperature, salinity, flow rate and "autotrophic processes". This requires careful integration in design of plumbing, circuitry, and overall spatial arrangement to meet such problems as handling of salt water, choice of non-toxic materials and resulting effects upon environments created for the organisms. The presence of salt water alone demands considerations for the welfare of your building and especially electrical equipment occurring in the area.

To date we have a family of apparati ranging from simple designs to complicated combinations providing various configurations of control features. The simplest item, of course, is the aquarium. When dealing with gametes or larval fishes typical aquaria may or may not serve as useful laboratory devices depending upon circumstances.

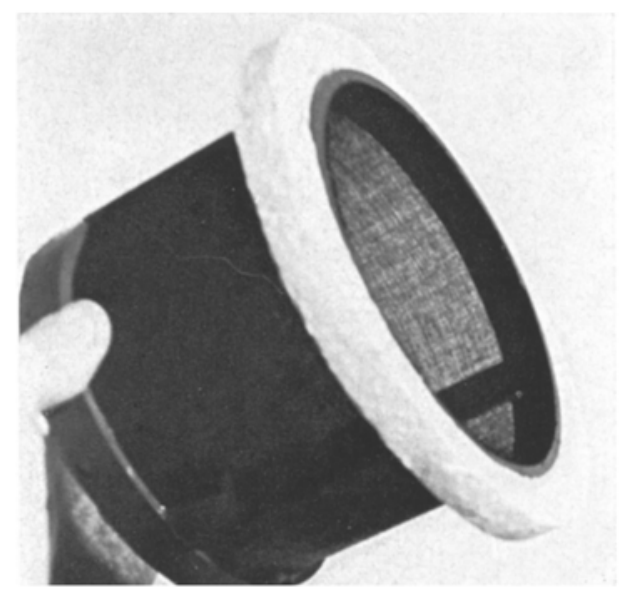

Fig. 1: Larval cage for raising fish larvae

Often there are requirements for moving or manoeuvering larvae and eggs into situations permitting convenient microscope observation. Crustacean larvae often do rather well in the laboratory and continue their development in culture dishes. We have subjected fry to similar procedures but have infrequently duplicated similar success with marine fish larvae. Using a combination of observations, gestalt and simple experiments, a procedure has been developed utilizing an 8 inch Carolina culture dish, placing the fish larvae in a "cage" permitting circulation and water changes with minimal disturbance of the larvae during observations of development. This arrangement may be linked circulation-wise to separate reservoirs containing living plants or water processors and providing dilution advantages of larger volumes per organism 
with the observational and food concentration advantages of the smaller volume culture dish. All of our circulation at the present time is accomplished with simple airlifts and siphons. Earlier experiments using magnetic driven impellors for circulation showed some promise, but dependability and degree of control have favored airlift systems at present.

Systematic tests of the effects of autotrophic organisms upon success of development of numbers of fish larvae in separate containers are presently underway to evaluate needs and adaptations to laboratory set-ups. Tests of different volume combinations, ranging from a Carolina dish with a 3 gallon autotrophic reservoir

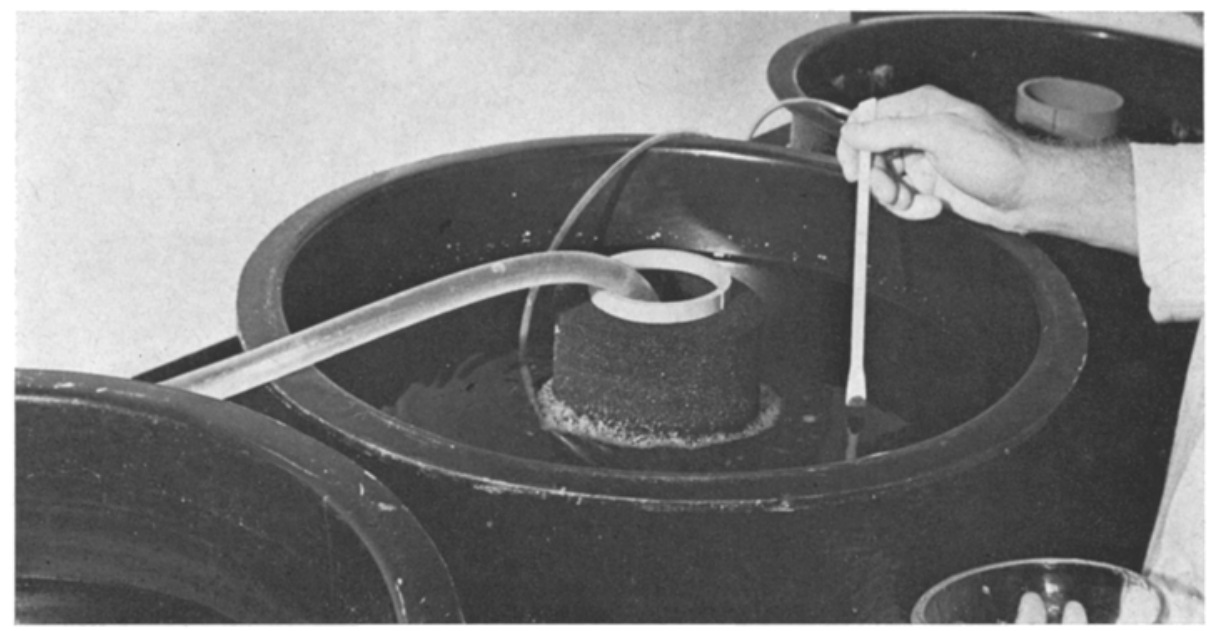

Fig. 2: Circular chamber (20 gallon) used for cultivating larval and juvenile aquatic organisms

circuit to a 20 gallon container in circuit with a 12 gallon autotrophic tank, are simultaneously underway. A specially designed 20 gallon container circulates water past eggs and newly hatched larvae contained in fine screened floating baskets. This round container (Fig. 2), with its water circulation rate under selective control, provides constant circulation conditions through the larval baskets. A third system, just completed, consists of 50 gallon rounded rectangular containers with subsand filters. These tanks are used principally for rearing of juveniles but also accept the larvae of species selected for experimentation and are chosen specifically as indicators to guide design and development of our equipment. In the continual testing of materials for side effects and possible toxicity on developing embryos, Brachydanio rerio (the fresh water zebra danio) provides a constant supply of eggs and larvae. For marine test species various forms are used, often chosen on the basis of their egg characteristics. Attached eggs are obtained from members of the fish families Gobiidae and Pomacentridae. Callionymidae, Serranidae, Carangidae, and Mugilidae have been used for sources of pelagic eggs. The latter two families listed contain species which have other applications and are of current interest to aquaculturists. Embryos and gametes have been obtained from these species through artificially induced and 
natural spawnings. Smaller species from the families named are useful due to their specific egg characteristics, various breeding seasons and adaptability to continual laboratory rearing.

In addition to testing of water qualities, types of circulation, and effects of associated plants, photoperiodism is regulated to test the effects of extending or controlling spawning periods. Initial tests utilizing several of the smaller species yield combinations of factors which are now being applied to larger species.

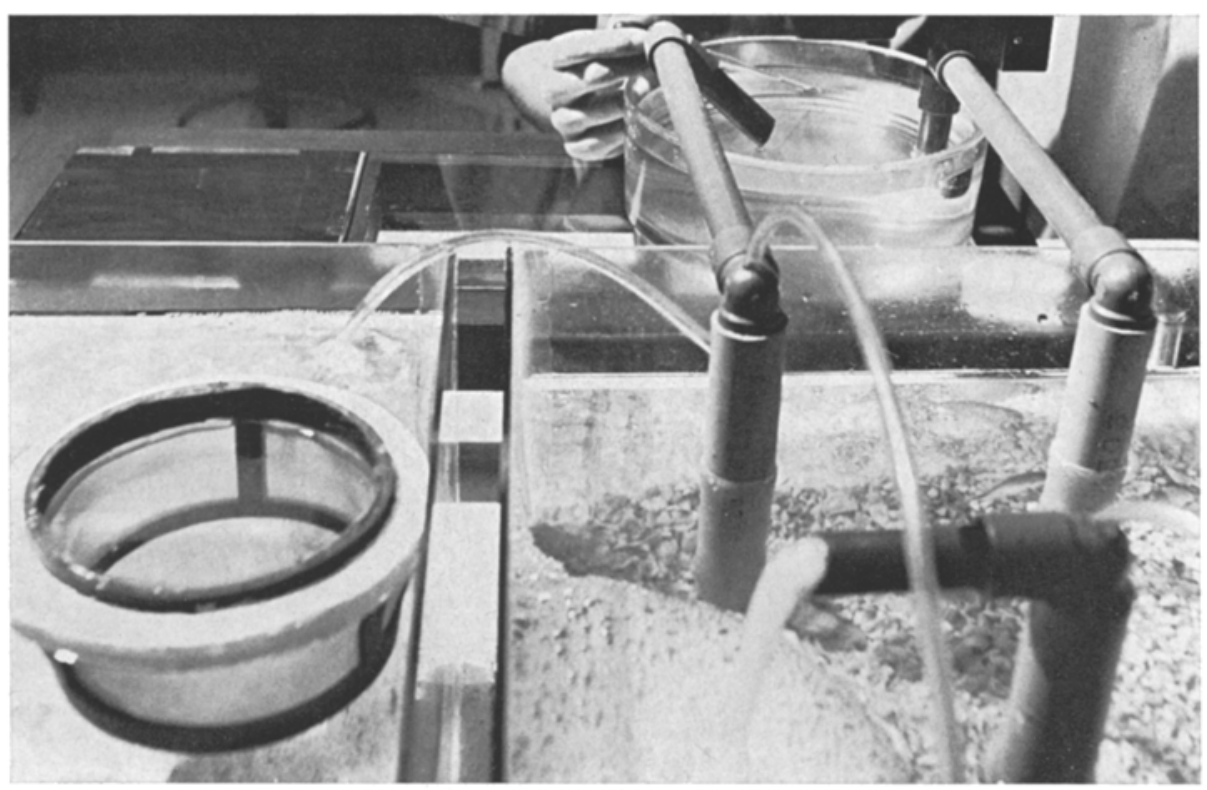

Fig. 3: Small containers such as the culture bowl and the larval cage have been successfully used for cultivating various fishes from egg to $20 \mathrm{~mm}$ juveniles. These containers exchange water with reservoirs under controlled conditions

The figures illustrate some of the apparatus used in tests of closed system fish rearing. In the research tank room there are three ranges of 50 gallon tanks, totalling 48 aquaria. The fibreglass tanks are pigmented black inside, and are illuminated by rheostat controlled full-spectrum fluorescent lamps. Internally, three large airlifts provide a controllable water circulation through a thick subsand filter of dolomite or Florida oolite. These tanks have proved to be quite successful in raising juvenile fish for experimentation. Figure 1 shows one of our simplest yet most successful devices for raising various fish larvae. The fine mesh larval cage shown consists of a styrofoam float collar and polyvinyl chloride frame which can be lined with a variety of netting types. The pomacentrids underwent successful embryonic development when hatched in the trap illustrated. The eggs came from a nest in South Florida.

Figure 2 shows feeding of juvenile pompano, Trachinotus carolinus maintained in the 20 gallon circular tank; because of its resemblance to a cauldron we fondly call it "the pot". The center cylindrical (polyurethene) foam filter apparatus in its 
PVC frame can be seen. The incoming vinyl pipe carries water returning from an external autotrophic culture container. Temperature sensors, heat exchangers and salinity monitors located externally in circuit with the pot can be used or bypassed via valve controls. The circular water motion within the pots has demonstrated beneficial effects upon several of the species tested. Larval cages may be placed in the pot and it was with this combination that pomacentrid embryos were raised. The external autotrophic reservoirs used with the pot use full wave length spectrum "Vitalights" to culture algae. A subsand filter also processes incoming water from the pot. In early tests mixed collections of pelagic plankters placed in pots with autotrophic tanks remained alive for several weeks. Subsequently we have found definite beneficial effects upon juvenile pompano Trachinotus carolinus.

In Figure 3 we have an autotrophic reservoir tank combined with a Carolina culture bowl yielding a system for continual monitoring of developing fish fry. The larvae may be raised either in cages in the autotrophic system or in external culture bowls or cages within culture bowls. The various combinations allow several variations of tests and controls.

\section{DISCUSSION AND CONCLUSION}

At this date, by using various techniques and experiments as stepping stones, sets of criteria have been developed for rearing larvae of several species of fishes. Researchers in this field normally state that live natural food is an absolute necessity in keeping fish larvae alive. One of our continual research programs is testing this premise. At the present time we have no conclusive results that this is, or is not, the case. By culturing various live foods, including algae and zooplankters, we continually seek successful techniques for supplementing wild foods with laboratory-formulated foods. However, at the present state-of-the-art in larval fish culture, only achieving increased hatch and survival is worthy to note. Data on comparative growth of marine fish larvae under differing conditions is a rare topic in current research reports.

Many research papers have been used to derive information for our ideas. Among the most useful in developing our present concepts have been the papers of SHELBourne (1965) presently at Port Erin, Isle of Man (Great Britain), and the more recent apparatus developments by Greve (1968) at Helgoland (Germany).

In conclusion, the raising of fish larvae from eggs and the production of eggs on a predictable basis presents a challenge of the highest order, particularly if aquaculture or mariculture endeavors are to be successfully achieved. Multiple approaches to problems must be used to enable us to devise and develop artificial ecosystems for rearing fish larvae and other organisms. Use of specifically chosen species for testing various combinations of controlled environmental factors will lead us to more sophisticated levels of understanding of the physiological requirements for development than we presently enjoy. 


\section{SUMMARY}

1. Various designs and techniques of closed system rearing of fish larvae are being developed using specific species chosen on the basis of their reproductive habits, ecological preference, and potential as environmental indicators.

2. The influence of the parameters of temperature, salinity, food, light, circulation, and the presence of autotropic organisms are tested using as criteria for the success of hatch and development.

3. To date, the results have produced several techniques which increase the percentage of success in raising fry and juvenile fishes.

Acknowledgements: The author wishes to acknowledge the invaluable assistance in all phases of this work by Miss G. Kurne and Mr. J. Peterson.

\section{LITERATURE CITED}

GREVE, W., 1968. The "planktonkreisel", a new device for culturing zooplankton. Mar. Biol. 1, 201-203.

Kat.Ber, F. A., 1970. Osmoregulation in decapod larvae as a consideration in culture techniques. Helgoländer wiss. Meeresunters. 20, 697-706.

Shelbourne, J. E., 1965. Rearing marine fish for commercial purposes. Rep. Calif. coop. oceanic Fish. Invest. 10, 53-63.

Author's address: Dr. W. P. Davis

Aquatic Sciences, Inc.

Boca Raton, Florida, USA 